\title{
Unusual presentation of localized gingival enlargement associated with a slow-growing odontogenic myxoma
}

\author{
Jaume Miranda Rius ${ }^{1}$, Alfons Nadal $^{2}$, Eduard Lahor $^{1}$, Beatus Mtui ${ }^{3}$ and Lluís Brunet ${ }^{4}$ \\ Unusual presentation of localized gingival enlargement associated with a subjacent tumoural pathology is reported. The patient was a \\ 55-year-old black male, whose chief complaint was a progressive gingival overgrowth for more than ten years, in the buccal area of the \\ anterior left mandible. According to the clinical features and the radiological diagnosis of odontogenic keratocyst, a conservative \\ surgery with enucleation and curettage was performed. Tissue submitted for histopathological analysis rendered the diagnosis of \\ odontogenic myxoma. After 12-month of follow-up, no evidence of recurrence was found. Clinicians should be cautious when facing any \\ gingival enlargement to avoid diagnostic pitfalls and to indicate the appropriate treatment.
}

International Journal of Oral Science (2013) 5, 172-175; doi:10.1038/ijos.2013.27; published online 31 May 2013

Keywords: gingival enlargement; jaw neoplasm; odontogenic tumour; myxoma; myxofibroma

\section{INTRODUCTION}

Gingival enlargement is defined as an abnormal growth of the gum tissue. It is associated with multiple factors including: inflammation, hormonal, drug use, neoplasm, genetic, systemic and idiopathic. ${ }^{1-3}$ Despite most of gingival overgrowths are generalized, occasionally this dimorphism can also show a localized gingival enlargement as a consequence of a longstanding proliferative and expansive process in the underlying structures: maxillary bone, periodontal ligament or dental tissues. ${ }^{3-5}$

Odontogenic tumours constitute a cluster of neoplasms that are derived from tissues and/or tissue remnants with potential to develop different dental tissues. ${ }^{6}$ Odontogenic myxoma $(\mathrm{OM})$ is a benign, locally invasive and aggressive, non-metastasizing neoplasm of the jaw bones. These tumours represent approximately 3\%-20\% of all odontogenic tumours. As it is often asymptomatic, the lesion may reach a considerable size before the patient discovers its existence. ${ }^{7-8}$

According to the World Health Organization classification odontogenic myxoma/myxofibroma, is composed of cells from the mesenchyme and/or odontogenic ectomesenchyme with or without odontogenic epithelium. ${ }^{9}$ Macroscopically $\mathrm{OM}$ has a whitish, translucent, mucinous appearance. It is uncapsulated and poorly demarcated, thus permeating the surrounding bone and soft tissue by expansion rather than as a result of cellular growth. This tumour has a low proliferation rate. Histopathologically, myxoma and/or myxofibroma are characteristically hypocellular. Microscopically these lesions are characterized by stellate and spindle-shaped cells embedded in a richly myxoid extracellular matrix, with little collagen. These cells present long cytoplasmatic prolongations that give to the tissue characteristics of immature mesenchyma. Cases with high amounts of collagen in their myxoid extracellular matrix are denominated myxofibromas. ${ }^{7,10}$
Radiographically, the tumour is seen as a unilocular or multilocular radiolucent lesion with well-defined borders, some of them having sclerotic trabeculations with different appearances. Displacement of teeth is a relatively common finding, although root resorption is rarely seen. $^{11}$

Current treatment ranges from curettage to block resection with wide margins with different rates of recurrence. Indeed, there is not a clearly established consensus about the surgical treatment of OM yet. ${ }^{12}$

This case report describes an atypical presentation of localized gingival enlargement associated with a slow-growing OM.

\section{CASE DESCRIPTION AND RESULTS}

A 55-year-old black male was attended at Dental \& Oral Department in Soweto General Hospital, Arusha (Tanzania), complaining of a growing swelling in the area of the anterior left mandible, involving the incisors and canine region (from 33 to 41 ). The patient explained a progressive localized gingival enlargement for more than ten years. $\mathrm{He}$ had neither smoking history nor other past medical history of note.

This extreme localized gingival enlargement measured $28 \mathrm{~mm} \times 33 \mathrm{~mm}$ in diameter with very well-defined contour and spherical shape. It is also remarkable that the extreme volume of this gingival overgrowth was mainly at the expense of the inserted broadband gingival distension. However, mucogingival line was completely preserved anatomically in spite of the huge expansion and long evolution of the process.

Painless tension and crepitation were palpable. Lesion size made difficult a correct lip-seal, caused gingival trauma during mastication and induced local tooth displacement in the affected area (Figure 1). No dental mobility was noted and dental vitality was normal. A moderate chronic periodontitis with abundant supra and sub gingival

${ }^{1}$ Departament d'Odontostomatologia, Facultat d'Odontologia, Universitat de Barcelona, Barcelona, Spain; ${ }^{2}$ Servei d'Anatomia Patològica, Hospital Clínic, Facultat de Medicina,

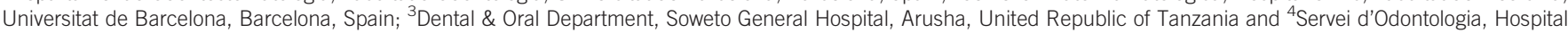
Universitari Sant Joan de Déu, Universitat de Barcelona, Barcelona, Spain

Correspondence: Dr J Miranda Rius, Departament d'Odontostomatologia, Facultat d'Odontologia, Universitat de Barcelona, Feixa Llarga, s/n, O8907 L'Hospitalet de Llobregat, Barcelona, Spain

E-mail: jmiranda-rius@ub.edu

Received 14 November 2012; accepted 22 April 2013 


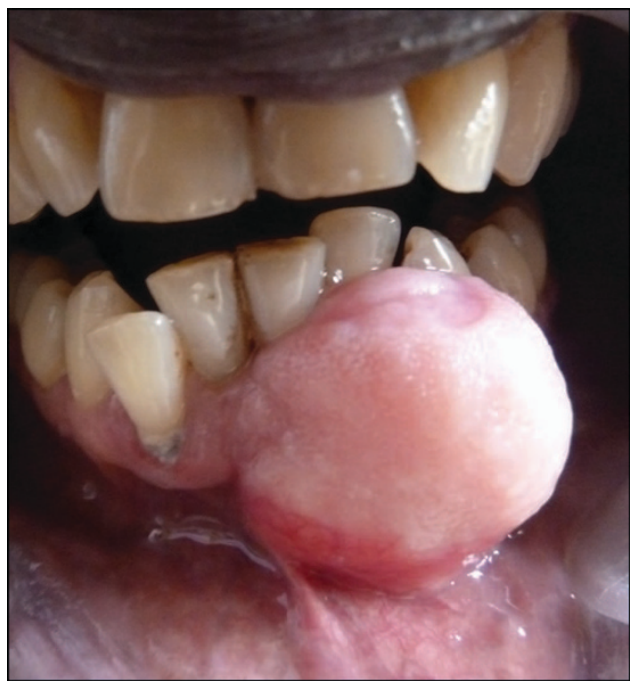

Figure 1 Clinical appearance. Intraoral frontal image of the extreme localized gingival enlargement involving the incisors and canine region (from 33 to 41).

calculus was diagnosed. Deep gingival pockets-pseudo pocketswith slight bleeding were registered on the periodontal charting around the localized enlargement.

Radiographically, there was an unilocular radiolucent lesion, inducing root displacement without resorption, between 33 and 32 teeth with well-defined borders suggesting a cystic, 'soap bubble' lesion. A computerized tomography was performed, showing an expansive and osteolytic single left mandibular lesion, with buccal and lingual cortical bone destruction and some internal calcifications but no compartments (Figure 2). The radiology report informed an odontogenic keratocyst. No dental structure was included in the lesion.

This patient was treated through a collaborative program supported by a nonprofit Professional Partnership. With the presumptive diagnosis, according to the clinical features and the local discomfort produced by the lesion, a conservative surgery with enucleation and curettage was performed without preoperative biopsy.

Periodontal internal bevel incision was designed, preserving the enormous broadband of keratinized gingiva, like a full-thickness flap procedure in the mandibular symphysis region. The lesion was not surrounded by any wall. Buccal cortical was completely effaced. After a thoroughly curettage of the quite soft tumoural tissue an important infrabony defect appeared which caused a considerable denuded radicular surface of the involved teeth (Figure 3a). Close to the amelocementaria line, a cortical protuberance $(5-7 \mathrm{~mm})$, consequence of the expansive process, had to be regularized in order to get some autologous bone and better flap adaptation. The whole defect was filled using a mixture of the bone previously collected and a bone graft substitute Straumann Bone Ceramic ${ }^{\circledR}$ (porous biphasic calcium phosphate). Some reabsorbable haemostat chips of Collagen Diacoll ${ }^{\circledR}$ (Collagen of porcine origin) were also used to stabilize this mixture.

The adjacent gingival area which had been in intimate contact with this lesion for so many years, presented a deep fibrotic reaction. This abnormal thick layer, adhering to the connective gingival tissue, was removed after being carefully dissected. A flap thinning was performed in order to achieve a proper replacement. After 12-month follow-up, no evidence of recurrence was found.

Tissue submitted for histopathological analysis consisted of several soft pieces that altogether measured up to $25 \mathrm{~mm} \times 15 \mathrm{~mm} \times 5 \mathrm{~mm}$
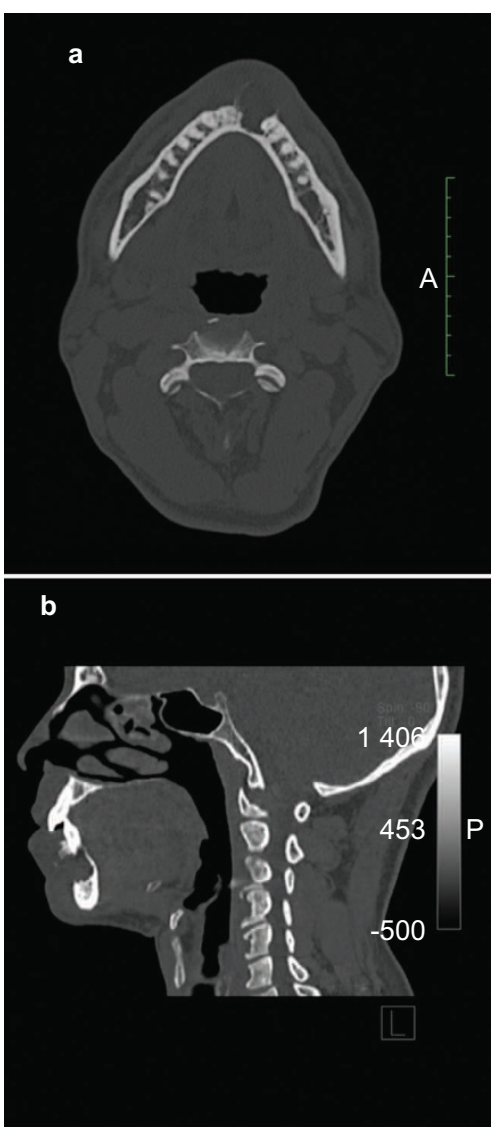

Figure 2 CT scan views. (a) Transverse view: a single osteolytic mandible lesion, with some internal calcifications without internal compartments. (b) Sagital view: notice buccal and lingual cortical bone destruction.
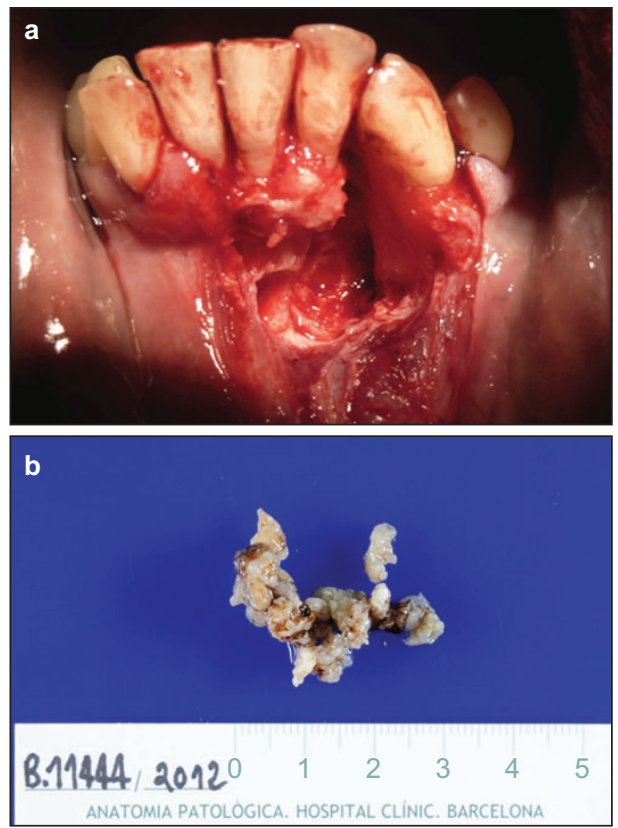

Figure 3 Macroscopic appearance. (a) Intraoperative image. Typical infrabony irregular defect in perforating punches. Notice the loose of periodontal insertion and the important radicular surfaces exposure around the involved teeth. (b) Macroscopic appearance of the resected tissue after fixation. 


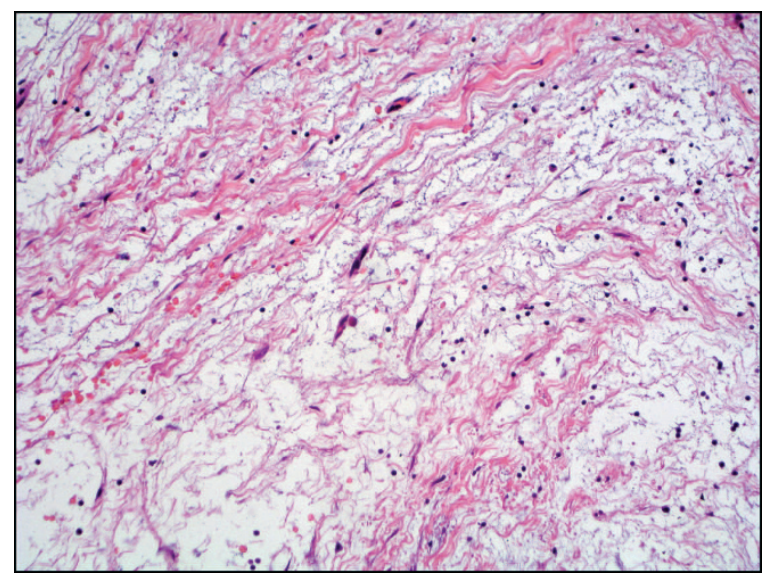

Figure 4 Microscopic appearance. Evenly distributed round cells embedded in a loose myxoid stroma with occasional spindle-shaped cells. Hematoxylin and eosin stain. Original maginification $\times 20$.

with a gray-whitish, translucent, mucinous appearance including an osseous fragment $4 \mathrm{~mm}$ long. The material was submitted 'in to' for histology (Figure 3b). Microscopically, the lesion was made up of an abundant loose mucoid or myxoid stroma with evenly distributed round cells with scarce randomly oriented spindle- or stellate-shaped cells of mesenchymal origin alternating with more highly cellular areas and eosinophilic areas of collagen deposition (Figure 4). Although thoroughly looked for, no cyst lining was found. Neither cellular pleomorphism, nor multinucleated cells, nor mitotic activity nor epithelial odontogenic rests were seen. Residual lamellar bone fragments were interspersed within the myxoid stroma. All these features rendered the histopathological diagnosis of odontogenic myxoma/myxofibroma.

\section{DISCUSSION}

Since its original description by Thoma and Goldman in 1947, the nature of odontogenic myxomas has been a matter of controversy. These neoplasms are thought to be derived from the mesenchyme of a developing tooth or from the periodontal ligament. ${ }^{13-14}$ However, some studies have found that the cells and the extracellular matrix of OM are different from the ectomesenchymal tissues of developing tooth. ${ }^{15-16}$

Odontogenic myxoma exhibits slow and asymptomatic expansion, sometimes resulting in a perforation of the cortical borders of the bone affected. Radiological examination plays a crucial role for the differential diagnosis of OM, which includes other pathological conditions like: odontogenic fibroma, fibrous dysplasia, ameloblastoma, dentigerous cyst, odontogenic keratocyst, central giant cell granuloma, osteosarcoma, fibrosarcoma, ossifying fibroma and chondrosarcoma. ${ }^{17-18}$

Although OMs can be found in several areas in both jawbones, the mandible is affected more frequently than the maxilla, and the posterior region is the most frequently affected location in both sites. ${ }^{10}$

The treatment of OMs has been most controversial. Indeed, there is not a clearly established consensus about the surgical treatment of OM yet. According to different authors, the recommended treatment modality depending on tumour size is either radical resection or conservative tumour excision. Different procedures have been proposed in the literature for OMs: enucleation and peripheral ostectomy, cryotherapy and radiotherapy. ${ }^{11-12,19}$ Nevertheless, the most used options remain enucleation with curettage and resection. The reported rate of recurrence after resection seems to be noticeably lower than after enucleation and curettage. ${ }^{19}$ The preferred protocol proposed by some authors is to perform a conservative surgery by enucleation and curettage when lesions are smaller than $3 \mathrm{~cm}$ and segmental resection with immediate reconstruction when bigger lesions are present. ${ }^{12}$

Other authors indicate a surgical treatment for OM that resembles the management for ameloblastoma solid type, especially when locally aggressive behaviour is present which includes: cortical bone perforation, major tumour expansion and adjacent tissue infiltration in a short period of time (weeks to months). A radical primary resection of the tumour with maximal preservation of surrounding anatomic structures is necessary with healthy anatomical borders of $0.5-1 \mathrm{~cm}$ beyond the radiographic tumour borders. ${ }^{11}$

Some authors use different bone grafts or allograft materials for filling residual bone defects after surgery. The autologous bone graft has ostoinductive, osteoconductive and osteogenetic properties and prevent from any possible viral infections transmission. However, the need of a second surgical donor site increases morbidity and stress for the patient, and the amount of bone tissue available is limited. Fresh-frozen human bone processed by the Tissue Bank, which provides osteoinductive and osteoconductive properties with major availability of bone for filling defects, can be considered a safe choice. Bone-graft substitutes should be osteoconductive, osteoinductive, biocompatible, bioresorbable, structurally similar to bone, easy to use and cost-effective. ${ }^{20-21}$

Myxomas/myxofibromas show a recurrence rate between 25\% and $43 \%$. These recurrences are the result of local invasion into cancellous bone beyond radiographically visible margins in the absence of encapsulation. The nature of this lesion, without a sheath but with an infiltrative growth of the myxomatous tissue into the adjacent bone, determines the high rate of relapse when conservative enucleation and curettage are performed. ${ }^{14}$ Other odontogenic tumours, like the keratocyst or the ameloblastoma show higher recurrence rates of 30\%-58.3\% and 55\%-90\%, respectively. ${ }^{22}$ These patients should be monitored for at least 2 years after the surgical intervention due to the higher rate of recurrence during this period. $^{7}$

\section{CONCLUSIONS}

To the best of our knowledge, there are no previous reports about such an extreme localized gingival enlargement associated with an odontogenic myxoma/myxofibroma for more than 10 years. This lesion involves periodontal tissues, inducing a large gingival expansive process in relation to a subjacent tumoural pathology.

This case is especially interesting because of its singularity, slow growing and for the extreme gingival localized dimorphism. It is also remarkable that the extreme volume of this overgrowth was mainly at the expense of the inserted broadband gingival distension, while the mucogingival line reference was anatomically preserved. Although histopathology provides the final diagnosis, radiological examination also plays an important role in the differential diagnosis. The management of choice is surgical and ranges from enucleation and $\mathrm{cu}$ rettage to complete resection and peripheral osteotomy according to its size. In this case, after 12-month follow-up, no evidence of recurrence was found.

Clinicians should be aware that any gingival enlargement can be of neoplastic nature although it could mimic the features of the much more common inflammatory processes, particularly at early stages, to avoid diagnostic pitfalls and to indicate the appropriate treatment. Patients must be monitored postoperatively for $2-5$ years in order to diagnose possible recurrence. 


\section{ACKNOWLEDGEMENTS}

Clínics Associats, a well-established Professional Partnership in Terrassa (Barcelona), deserves a special mention for leading and supporting the KiliBarnaDental project at Soweto General Hospital in Arusha, United Republic of Tanzania, East Africa. The authors thank Straumann, SA (Spain) for its contribution.

1 Brunet LI, Miranda J, Farré M et al. Gingival enlargement induced by drugs. Drug Saf 1996; 15(3): 219-231.

2 Clocheret K, Dekeyser C, Carels C et al. Idiopathic gingival hyperplasia and orthodontic treatment: a case report. J Orthod 2003; 30(1): 13-19.

3 Rodríguez Y, Baena R, Rizzo S et al. Mandibular traumatic peripheral osteoma: a case report. Oral Surg Oral Med Oral Pathol Oral Radiol Endod 2011; 112(6): 44-48.

4 Perrotti V, Rubini C, Fioroni $\mathrm{M}$ et al. Soft tissue myxoma; report of an unusual case located on the gingiva. J Clin Periodontol 2006; 33(1): 76-78.

5 Rawal YB, Mustiful-Martín D, Rosebush MS et al. Slow-growing gingival mass. Oral Surg Oral Med Oral Pathol Oral Radiol 2012; 113(2): 161-167.

6 López Arranz JS, Junquera Gutiérrez LM. [Tumores odontogénicos. Generalidades. Clasificación. Formas clínicas. // Bascones A. Tratado de Odontología.] Madrid: Trigo Ediciones, 1998: 3927-3940. Spanish.

7 Buchner A, Merrell PW, Carpenter WM. Relative frequency of central odontogenic tumors: a study of 1088 cases from Northern California and comparison to studies from other parts of the world. J Oral Maxillofac Surg 2006; 64(9): 1343-1352.

8 Gomes CC, Diniz MG, Duarte AP et al. Molecular review of odontogenic myxoma. Oral Oncol 2011; 47(5): 325-328.

9 Barnes L, Eveson J, Reichart P et al. World Health Organization Classification of Tumours. Pathology and Genetics of Tumours of the Head and Neck. Lyon: IARC, 2005.

10 Martínez-Mata G, Mosqueda-Taylor A, Carlos-Bregni R et al. Odontogenic myxoma: clinicopathological, immunohistochemical and ultrastructural findings of a multicentric series. Oral Oncol 2008; 44(6): 601-607.
11 Leiser Y, Abu-El-Naaj I, Peled M. Odontogenic myxoma-a case series and review of the surgical management. J Craniomaxillofac Surg 2009; 37(4): 206-209.

12 Boffano P, Gallesio C, Barreca A et al. Surgical treatment of odontogenic myxoma. J Craniofac Surg 2011; 22(3): 982-987.

13 Günhan U, Arpak N, Celasun B et al. Odontogenic myxoma. Report of a periodontallylocated case. J Periodontol 1991; 62(6): 387-389.

14 Simon EN, Merkx MA, Vuhahula E et al. Odontogenic myxoma: a clinicopathologica study of 33 cases. Int J Oral Maxillofac Surg 2004; 33(4): 333-337.

15 Moshiri S, Oda D, Worthington P et al. Odontogenic myxoma: histochemical and ultrastuctural study. J Oral Pathol Med 1992; 21(9): 401-403.

16 Schmidt-Westhausen A, Becker J, Schuppan D et al. Odontogenic myxoma-characterisation of the extracellular matrix (ECM) of the tumour stroma. Eur J Cancer B Oral Oncol 1994; 30B(6): 377-380.

17 Zhang J, Wang H, He X et al. Radiographic examination of 41 cases of odontogenic myxomas on the basis of conventional radiographs. Dentomaxillofac Radiol 2007; 36(3): 160-167.

18 Noffke CE, Raubenheimer EJ, Chabikuli NJ et al. Odontogenic myxoma: review of the literature and report of 30 cases from South Africa. Oral Surg Oral Med Oral Pathol Oral Radiol Endod 2007; 104(1): 101-109.

19 Adebayo ET, Ajike SO, Adekeye EO. A review of 318 odontogenic tumors in Kaduna, Nigeria. J Oral Maxillofac Surg 2005; 63(6): 811-819.

20 Albanese M, Nocini PF, Fior A et al. Mandibular reconstruction using fresh frozen bone allograft after conservative enucleation of a mandibular odontogenic myxoma. $J$ Craniofac Surg 2012; 23(3): 831-835.

21 de Macedo LG, de Macedo NL, do Socorro Ferreira Monteiro A. Fresh-frozen human bone graft for repair of defect after adenomatoid odontogenic tumour removal. Cell Tissue Bank 2009; 10(3): 221-226.

22 Ali M, Baughman RA. Maxillary odontogenic keratocyst: a common and serious clinical misdiagnosis. J Am Dent Assoc 2003; 134(7): 877-883.

(c) This work is licensed under a Creative Commons

Attribution-NonCommercial-NoDerivative Works 3.0

Unported License. To view a copy of this license, visit http:// creativecommons.org/licenses/by-nc-nd/3.0 